\title{
Perception and Knowledge of Tuberculosis and Its Services among Slum Dwellers in Chhattisgarh
}

\author{
Janmejaya Samal \\ Medical Consultant, Catholic Health Association of India, Chhattisgarh, India
}

\section{Abstract}

Background: The level of knowledge and behavior of tuberculosis (TB) patients and the vulnerable population can affect the control of TB in a particular community. Objective: The main objective of this study was to assess the level of knowledge and behavior regarding TB among slum dwellers in Chhattisgarh, India. Materials and Methods: A total of 100 families were selected from two different slum areas in Durg district of Chhattisgarh through simple random sampling technique. A structured questionnaire was used to collect the information from the slum dwellers. Results: Ninety-five percent of the respondents knew that TB is caused by bacteria, $82 \%$ knew that TB is transmissible, $63 \%$ were aware of different modes of TB transmission, $97 \%$ could tell about the symptoms of TB, and $76 \%$ of participants were aware about the curability of TB. Seventy-five percent of the slum dwellers were aware that TB treatment is free of cost at public health facilities; $68 \%$ were aware that TB is preventable, and $91 \%$ could tell about various preventive measures of TB. It was observed from this study that the slum dwellers have relatively poor knowledge about the modes of TB transmission and its preventability showing that proper health education approaches must be implemented to bring down this knowledge gap. Conclusion: Health education and awareness programs need to be carried out to further improve the knowledge of slum dwellers. This would ensure their seeking proper help at appropriate time and place and take precautionary measures against contracting TB.

Keywords: Behavior, knowledge, slum dwellers, tuberculosis, vulnerable population

\section{INTRODUCTION}

Since the times immemorial, tuberculosis (TB) has affected many civilizations around the world and has been a major reason for many death tolls during the earlier days. It remains as the number one killer infectious disease among the adult population in the developing countries even today. The WHO's 1990 global disease burden report ranked TB in the seventh position and expected to continue the same till 2020 in terms of morbidity ${ }^{[1]}$ India being the second most populous country in the world contributes to one-fourth of global TB incidence. In 2012, out of 8.6 million cases, 2.3 million cases were estimated to be from India. More adults die due to TB than from any other infectious disease with devastating social and economic consequences. ${ }^{[2]}$ In India, TB continues to be a devastating health crisis with more than 300,000 deaths, 2.2 million new cases, and economic loss of $\$ 23$ billion $(\leq 14.9$ billion; $€ 20.3$ billion) each year. ${ }^{[3]}$

Vulnerable populations are at greater risk of contracting the disease and spreading the same in the nearby community. This

\begin{tabular}{|l|l|}
\hline \multicolumn{2}{|c|}{ Access this article online } \\
\hline Quick Response Code: & Website: \\
& www.ijrconline.org \\
\cline { 2 - 2 } & \\
\hline
\end{tabular}

is primarily owing to their living style and the socioeconomic status. Furthermore, the level of knowledge and behavior of TB patients and the vulnerable population can affect their health-seeking behavior and thereby disease control at community level. This is of paramount importance as TB is a chronic infectious disease and requires protracted treatment. Appropriate education will help individuals and families seek medical care as per their own choice at an appropriate place and time ${ }^{[4,5]}$ Although the morbidity and mortality due to TB has reduced to a noticeable level with the implementation of Revised National Tuberculosis Control Programme and involvement of newer techniques and strategies, there is still a gap in access by special population and missing of cases that requires prompt attention from the public and private sectors

Address for correspondence: Dr. Janmejaya Samal, C/O Mr. Bijaya Ketan Samal, Pansapalli, Bangarada, Gangapur, Ganjam - 761 123, Odisha, India. E-mail: janmejaya_samal@yahoo.com

This is an open access article distributed under the terms of the Creative Commons Attribution-NonCommercial-ShareAlike 3.0 License, which allows others to remix, tweak, and build upon the work non-commercially, as long as the author is credited and the new creations are licensed under the identical terms.

For reprints contact: reprints@medknow.com

How to cite this article: Samal J. Perception and knowledge of tuberculosis and its services among slum dwellers in Chhattisgarh. Indian J Respir Care 2017;6:828-31. 
as well as other partners. A greater degree of awareness is required among the vulnerable population regarding TB and the medical services so that they can avail them at appropriate time and place, hopefully leading to a TB-free society.

This study aimed to assess the knowledge of slum dwellers about TB about the health services available for TB care and their behavior toward TB care and control.

\section{Materials and Methods \\ Sampling frame and technique}

Simple random sampling technique was used to obtain the desired number of households in two different slums, Bajranganagar and Khursipar, in Durg district of Chhattisgarh. The selected area was initially looked into for the feasibility of the study in terms of number of households. A list of hundred households was then obtained as per serial numbers from one end to the other from each of these sites. These numbers were written in small pieces of papers and kept in two different bowls, labeled as Bajranganagar and Khursipar. From each of these two bowls, fifty chits were randomly picked up and kept separately for each of these two sites. These hundred households formed the sample of this study.

\section{Determination of sample size}

As a cross-sectional study, the sample size should have been determined based on an estimated prevalence rate of knowledge among the slum population using the formula $4 \mathrm{PQ} / \mathrm{L}^{2}$. However, the same could not be arrived at owing to unavailability of findings in similar areas in Chhattisgarh. Thus, the sample size was deliberately chosen and kept to 100 households.

\section{Data collection tool (the questionnaire)}

The tool used in this study was a structured questionnaire. The questionnaire was translated into Hindi and then used to suit the local needs. A total of eight questions were asked to assess the knowledge and behavior about TB and its services among the slum dwellers in Chhattisgarh.

\section{RESULTS}

The study was carried out in a slum area to understand the knowledge and behavior of slum dwellers for TB and the services linked with it. The questionnaire comprised a total of eight questions pertaining to their understanding about TB and the medical services available [Table 1].

\section{DISCUSSION}

The first question assessed the knowledge of slum dwellers regarding the cause of TB with four options; bacteria, past $\mathrm{deed} / \mathrm{sin}$, demon, and all of these. Ninety-five percent of the respondents reported that bacteria caused TB. A similar study among the general patients in a tertiary care hospital in West Bengal revealed that $16.81 \%(n=464)$ of the respondents knew that $\mathrm{TB}$ is caused due to infection. ${ }^{[6]}$ This clearly indicates that

\begin{tabular}{lc}
\hline $\begin{array}{l}\text { Table 1: Knowledge level of study participants about } \\
\text { tuberculosis }(\boldsymbol{n = 1 0 0})\end{array}$ & Correct responses (\%) \\
\hline Questions & 95 \\
\hline What causes TB? & 82 \\
Does TB transmit from one person to other? & 63 \\
What are the modes of TB transmission? & 97 \\
What are the symptoms of TB? & 76 \\
Is TB curable? & 75 \\
Is TB treatment free of cost at public health & \\
facilities? & 68 \\
Can TB be prevented? & 91 \\
What are the preventive measures of TB? &
\end{tabular}

TB: Tuberculosis

people no longer believe that TB is being caused by something other than bacteria/infection. The second question was about the communicability of TB. Eighty-two participants $(82 \%$, $n=100)$ knew that TB is transmitted from one person to another. Five participants reported that TB does not transmit from person to person $(5 \%, n=100)$, three participants were not sure $(3 \%, n=100)$, and 10 participants $(10 \%, n=100)$ reported that they do not know. In a similar study, among the caregivers of pediatric TB patients, it was found that $45 \%(n=151) \mathrm{knew}$ that $\mathrm{TB}$ is a transmissible disease. ${ }^{[7]}$

The third question was about the modes of TB transmission with multiple choices such as; cough/breath, sharing cups, sharing utensils, through body contact or sharing clothes, all of these, none of these. Among different options, respondents said that cough is the main mode of TB transmission. Here the knowledge was also high compared to other studies. In the West Bengal study among general patients in a tertiary care hospital, the correct response to modes of TB transmission was elicited in only $31.47 \%(n=464)$ of the respondents. ${ }^{[6]}$ Among the slum dwellers of Surat city, this response was $57.8 \%(n=218) .{ }^{[8]} \mathrm{In}$ the pediatric caregivers in North Gujarat region, the response was correct in $68 \%(n=151) .{ }^{[7]}$ This knowledge among the suspected and confirmed TB cases in a medical college setting was found to be $80.4 \%(n=450)$. ${ }^{[9]}$

The fourth question was to assess the knowledge and perception of slum dwellers regarding the symptoms of TB with multiple choices such as persistent cough for 2 or more weeks, sputum with blood, chest pain, weight loss, loss of appetite, fever with sweating, all of these, and none of these. Among the study participants, $97 \%$ of the study participants were able to tell the symptoms of TB. Different studies in Indian communities show considerable level of knowledge of TB symptoms among different population segments. In an urban slum in Surat city of Gujarat, $84.4 \%, 66.2 \%, 69.72 \%$, and $23.85 \%(n=218)$ of the slum dwellers reported fever, cough, weight, and hemoptysis as the symptoms of TB. ${ }^{[8]} 62.3 \%(n=151)$ of the pediatric caregivers in North Gujarat region could specify one or other symptoms of TB. ${ }^{[7]}$ Similarly, $8 \%$ and 64\% $(n=2721)$ of Saharia tribes in Central India mentioned cough and coughing blood as the symptoms of TB in a cross-sectional study. ${ }^{[10]}$ 
Similarly, among the suspected and confirmed TB cases, in a cross-sectional study, the most commonly reported TB symptoms were cough $(84.4 \%, n=450)$ and cough with sputum $(77.8 \%, n=450) .{ }^{[8]}$ Among pulmonary TB patients in a tertiary care hospital in West Bengal, the most commonly reported symptoms were also cough and cough with sputum, and among the general patients, $62.07 \%(n=464)$ reported that cough was again the most commonly known symptom of TB among the others. ${ }^{[6]}$ Cough as the most commonly known symptoms of TB is further substantiated by another study in an urban slum of Puducherry where $82 \%(n=395)$ of the households reported it as the most commonly known symptoms. ${ }^{[11]}$ From all these studies, it is clearly evident that people in different communities in India know that cough and cough with sputum are the most common symptoms of TB.

The fifth question was asked to assess their knowledge regarding the curability of TB with option; yes, no, may or may not, do not know. Seventy-six percent of the respondents reported that TB is curable. In one of the studies, $92.2 \%(n=218)$ of the slum dwellers of Surat city responded that TB can be cured completely. ${ }^{[8]} 58.9 \%(n=151)$ of the pediatric caregivers in North Gujarat region reported that TB can be curable. ${ }^{[7]}$ Similarly, $82 \%(n=2721)$ of the Saharia tribes in Central India reported that TB is treatable ${ }^{[10]}$ Among pulmonary TB patients in a tertiary care hospital in West Bengal, 38\% $(n=100)$, and among the general patients, $82.76 \%(n=464)$ reported that TB is curable. ${ }^{[6]}$

The sixth question was asked to assess the knowledge and perception of participants regarding the availability of free treatment services for TB with choices; yes, no, may or may not, do not know. Seventy-five percent of the respondents were aware of free treatment option at public health facilities. Awareness among people of other Indian communities regarding the availability of free treatment was variable and was $29.81 \%$ in the study by Mahida et al.$^{[8]}$ and $84.2 \%$ in the study by Chinnakali et al. ${ }^{[1]}$

The seventh question assessed their knowledge and perception regarding the preventability of TB with options; yes, no, may or may not, do not know. Sixty-eight percent of the participants were aware that TB is preventable. A similar study which assessed the awareness and perception of TB among the general population in Delhi revealed that $98.2 \%$ of the respondents were aware that TB can be prevented. ${ }^{[12]}$ This indicates that people need more health education to make them aware that TB is preventable with various precautionary and preventive strategies which would obviously help them in preventing themselves from contracting TB.

The last question was asked to assess their knowledge about various preventive measures for TB; options being covering mouth and nose when coughing or sneezing, avoid sharing cups, using separate rooms, early treatment, avoiding body contact/handshaking, all of these, and none of these. It was observed that $91 \%$ of the study participants were aware of one or other type of preventive measures for TB. This figure does not indicate a complete knowledge regarding TB. Rather, they were only aware of one or other type of preventive measures. Among the Saharia tribes, as per one of the cross-sectional studies, $29 \%(n=2721)$ of the participants reported that covering the mouth and nose while coughing and sneezing can prevent the spread of TB. ${ }^{[9]} 48.43 \%$ slum dwellers in Puducherry reported that covering mouth with handkerchief while coughing and sneezing can prevent the spread of TB. ${ }^{[11]}$ A similar study among the slum dwellers in Bangalore city revealed that $40 \%$ of the participants were aware of the cough hygiene measures to prevent the spread of TB among family members. ${ }^{[13]}$ Another study which assessed the awareness and perception of TB among the general population in Delhi revealed different measures of preventive measures. $89.5 \%$ of the study participants reported that treatment of patients is the most important preventive measure. The other responses were cough hygiene (26.6\%), hospitalization of the patient $(25.0 \%)$, and use of separate utensils/separate consumption of food by the patient $(9.1 \%) .^{[12]}$ This may not be a good sign as only complete knowledge can make them avoid exposure that causes TB among them. Partial knowledge can create confusion among the slum dwellers.

\section{Conclusion}

Knowledge and perception regarding a particular health condition help the general population as well as the patients in taking right help at the right time. It helps them take preventive and precautionary measures of that disease. In this particular study, although the level of knowledge was found to be relatively high, it was not absolute. Thus, health education and awareness activities need to be carried out in slum areas as these people are vulnerable to TB owing to their lifestyle and socioeconomic conditions.

\section{Financial support and sponsorship}

Nil.

\section{Conflicts of interest}

There are no conflicts of interest.

\section{RefEREnCES}

1. Murray CJ, Lopez AD. The Global Burden of Disease: A Comprehensive Assessment of Mortality and Disability from Diseases, Injuries, and Risk Factors in 1990 and Projected to 2020; Summary. Geneva, Switzerland: WHO; 1996.

2. Central TB Division. TB India 2014. Revised National TB Control Programme. Annual Status Report. New Delhi: Central TB Division, Ministry of Health and Family Welfare, Government of India; 2012.

3. Udwadia ZF, Mehra C. Tuberculosis in India. BMJ 2015;350:h1080.

4. Samal J, Dehury RK. Role of families in tuberculosis care: A case study. Muller J Med Sci Res 2016;7:150.

5. Samal J. Health seeking behaviour among tuberculosis patients in India: A systematic review. J Clin Diagn Res 2016;10:LE01-6.

6. Das P, Basu M, Dutta S, Das D. Perception of tuberculosis among general patients of tertiary care hospitals of Bengal. Lung India 2012;29:319-24.

7. Jani Y, Bhambhani GD, Thakor N. Knowledge and awareness of tuberculosis in caregivers of paediatric tuberculosis patients of north Gujarat region, India: A cross sectional study. Int J Res Med Sci 2015;3:3572-5.

8. Mahida HD, Shroff KN, Kesur TD, Patel NB. Are urban slum dwellers 
Samal: Knowledge and perception of slum dwellers on TB

aware about tuberculosis? A cross sectional study in Surat City. Natl J Community Med 2014;5:346-8.

9. Deepak D, Khare DC, Shankar P, Singh D, Lakhani P, Tutu S, et al. Assessment of knowledge, attitude and practice about tuberculosis and its treatment in India. World J Pharm Res 2015;4:2181-6.

10. Muniyandi M, Rao VG, Bhat J, Yadav R, Sharma RK, Bhondeley MK. Health literacy on tuberculosis amongst vulnerable segment of population: Special reference to Saharia tribe in central India. Indian J Med Res 2015;141:640-7.

11. Chinnakali P, Ramakrishnan J, Vasudevan K, Gurumurthy J,
Upadhyay RP, Panigrahi KC. Level of awareness about tuberculosis in urban slums: Implications for advocacy and communication strategy planning in the National program. Lung India 2013;30:139-42.

12. Sharma N, Malhotra R, Taneja DK, Saha R, Ingle GK. Awareness and perception about tuberculosis in the general population of Delhi. Asia Pac J Public Health 2007;19:10-5.

13. Suganthi P, Chadha VK, Ahmed J, Umadevi G, Kumar P, Srivastava R, et al. Health seeking and knowledge about tuberculosis among persons with pulmonary symptoms and tuberculosis cases in Bangalore slums. Int J Tuberc Lung Dis 2008;12:1268-73. 